\title{
The quality analysis and countermeasure study for the matriculating of the postgraduate students of the armament specialty
}

\author{
Xuegong HUANG ${ }^{1, a}$, Zhiping Xie ${ }^{1, b}$, Xinjie Wang ${ }^{1, c}$ \\ ${ }^{1}$ School of Mechanical Engineering, Nanjing University of Science and Technology, Nanjing \\ 210094, China \\ ahuangxg@njust.edu.cn, b1225014833@qq.com, xjwang@njust.edu.cn
}

Keywords: postgraduate student, armament specialty, enrollment propaganda

Abstract:Based on analyzing the enrollment data of the postgraduate of NJUST from year 2010 to 2014 , for the matriculating of the postgraduate students of the armament specialty, there are several flaws as follows: Fewer students came from key universities and serious in inbreeding, the examinee regional excessive concentration and the publicity area needs to be further expanded, and the nationwide examination score of the armament specialty students was low. According to the advantages of the school, some suggestions were given as follow: Attract outstanding students by the characteristics of armament and advantage of discipline, exerting the effect of the celebrated teachers to attract outstanding students, giving full play to the advantages of excellent students, attracting good students by lineage and guide.

\section{Introduction}

All The postgraduate students matriculating quality refers to the level that the students who master the basic theory and system knowledge, as well as the scientific spirit and attitude to learning that could satisfy the requirement of postgraduate students training at the initial stage of graduate education. The higher quality matriculates should have solid academic foundation, the ability to flexibly apply knowledge, perfect psychological quality and cultural accomplishment ${ }^{[1,2]}$. At present, the matriculate quality is evaluated by the score of the Postgraduate Entrance Examination and the second interview of each school, as well as the student's education background and where the examinee came from $^{[3,4]}$.

In order to improve the level of our military equipment and build a strong army through science and technology, high-quality technical talents with innovative spirit and international outlook should be trained, and the training of defense specialties postgraduate students is the talents output base ${ }^{[5]}$. The matriculate quality of defense specialties postgraduate students is the basis to train this kind of professional, it related to the training quality and level of military personnel ${ }^{[5]}$. This paper taken the school of mechanical engineering of Nanjing University of Science and Technology (NJUST) as an example, statistics the data of 4 armament specialty for nearly 5 years, including weapon system and application engineering, aircraft and weapon launch theory and technology, aviation aerospace propulsion theory and engineering, and artillery automatic weapons and ammunition engineering, study the matriculate quality of the defense specialties postgraduate students, and it can provide theoretical guidance for the enrollment of the defense specialties student in the future.

The enrollment quality of the military direction postgraduate students in the school of mechanical engineering of NJUST in recent five years

The examine data information from 2010 to 2014 was analyzed, including the candidate's score distribution, universities level, and area of undergraduate school and so on. The problems about the enrollment quality of the military direction postgraduate students were found through data mining and comparative analysis.

Figure 1 shows the distribution column chart that the students who attended the second interview and come from different levels colleges and universities in the school of mechanical engineering of NJUST in recent five years. According to the figure 1, the series 1 is the total number of each year to 
attend the second interview, the series 2 is the total number that the students who came from the 211 colleges and universities, the series 3 is the total number that the students who came from NJUST, the series 4 is the total number that the students who came from NJUST and the applied major is the armament specialty. As can be seen from the figure 1, the number that the students who came from 211 was very few, it only account for about more than ten percent. Although the ratio has a tendency to increase year by year, but the increasing proportion is small.

Specific analysis, the second interview students from 211 schools, most of them were from NJUST, and the percentages from year 2010 to 2014 were $64 \%, 82 \%, 90.5 \%, 80.8 \%$, and $70.7 \%$ respectively, it seems that the excellent students mainly came from them university themselves. In detailed, the number of the attending the second interview students who came from 211 school were $8,9,26,18$, 26 respectively, and the number of the students who came from them university themselves were 6,8 , $25,18,26$, respectively, in recently 5 years. By these data can be seen, there were more 211 school students can achieve the second-round exam qualification relative to other civil major students, but more than $95 \%$ of the students came from the university itself. In this case, it is happy for us that the excellent undergraduate students in our school who select defense specialties for further study, on the other hand, there is also a problem of inbreeding, and the managers should take measures to diversify the source of the candidates.

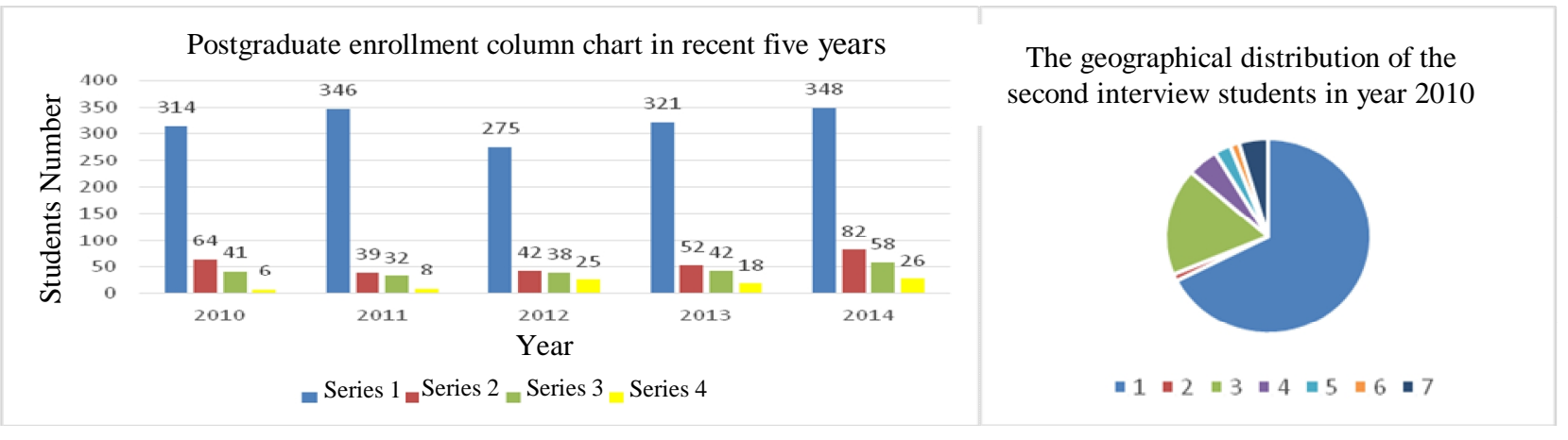

Fig1. School of mechanical engineering postgraduate enrollment column chart
Fig 2. The geographical distribution of the second interview students in year 2010

The examinee regional excessive concentration and the publicity area needs to be further expanded. According to the geographical location, China was divided into seven areas, including: (1) East China, including Shanghai, Shandong, Jiangsu, Anhui, Zhejiang, Fujian; (2) South China, including Guangdong, Hainan, Guangxi Zhuang Autonomous Region; (3) Central China, including Hubei, Hunan, Henan, Jiangxi; (4) North China, including Beijing, Tianjin, Hebei, Shanxi, Inner Mongolia Autonomous Region; (5) Northwest China, including Ningxia Hui Autonomous Region, Xinjiang Uygur Autonomous Region, Qinghai, Shanxi, Gansu; (6) Southwest China, including Chongqing, Sichuan, Yunnan, Guizhou, Tibet Autonomous Region; (7) Northeast Chain, including Liaoning, Jilin, Heilongjiang; (8) Hong Kong, Macau and Taiwan Regions, including Hong Kong, Macao, Taiwan). In year 2010 to 2014, the geographical distribution of the candidates who had the qualification to attend the second interview as shown in figure $2 \sim 6$ respectively.

From figure $2 \sim 6$, it can be seen that the second-round exam students in the school of mechanical engineering, there more than 70\% came from East Chain, and then from Central China and North China. For the retesting students of East Chain, most of them came from Anhui, Jiangsu and Shandong. The armament specialty is a national particular specialty in NJUST, and they have special advantages in equipment manufacturing, information processing, automation and intellectualization. According to the needs of national defense construction, the school should enhance the admissions propaganda in northwest region, especially in Xi'an, Chongqing, Sichuan and Gansu. Because there are many key universities and weapons industry research institute, and the students are very excellent. The admissions office should take steps to attract good examinee entering for the armament specialty examination in the future, such as expanding the propaganda region, changing the 
students' structure, paying attention to school characteristics and so on, and then attracting more first-class disciplines examinee from the top universities of other provinces.

The geographical distribution of the second interview students in year 2011

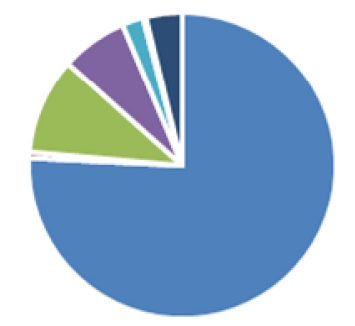

$=1=2-3=4=5=6 \pm 7$

Fig 3.The geographical distribution of the second interview students in year 2011

The geographical distribution of the second interview students in year 2013

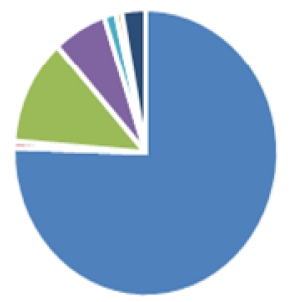

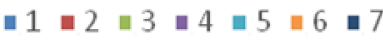

Fig 5.The geographical distribution of the second interview students in year 2013
The geographical distribution of the second interview students in year 2012

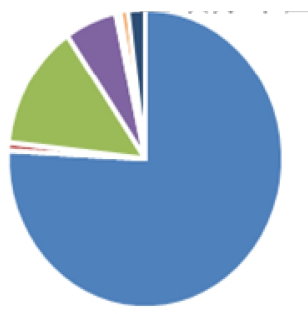

$\because 1: 2=3: 4=5: 6: 7$

Fig 4.The geographical distribution of the second interview students in year 2012

The geographical distribution of the second interview students in year 2014

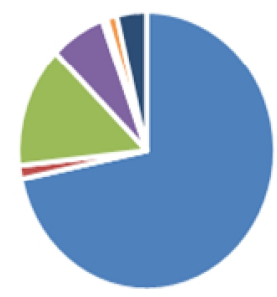

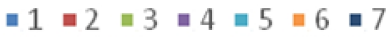

Fig 6.The geographical distribution of the second interview students in year 2014

The nationwide examination score of the armament specialty was low, and need to choose the good students from second interview. Figure 7 shows the averages deviation between the total averages of all the second-round exam students and the total averages of one major direction in the school of mechanical engineering of NJUST from year 2010 to 2014 . The ordinate of figure 7 expresses the averages deviation, and the abscissa number is respectively: "1" denotes mechanical manufacturing and automation, " 2 " denotes mechanical electronic engineering, and " 3 " denotes mechanical design theory and mechanical engineering, "4" denotes vehicle engineering, " 5 " denotes measurement technology and instruments, "6" denotes aerospace propulsion theory and engineering, weapon systems and engineering, aircraft and weapon launch theory and technology, "7" denotes artillery, automatic weapons and ammunition engineering direction.

As shown in figure 7, the GPA of the armament specialty are less than the total GPA of the school of mechanical engineering, and the gaps were more than 20 points. That is to say, compared with the civil professional examinee, the armament specialty examinees had poorer basic knowledge. Aiming at this problem, the admissions office can strengthen the second-round exam evaluation, choose the students who have strong comprehensive ability. 


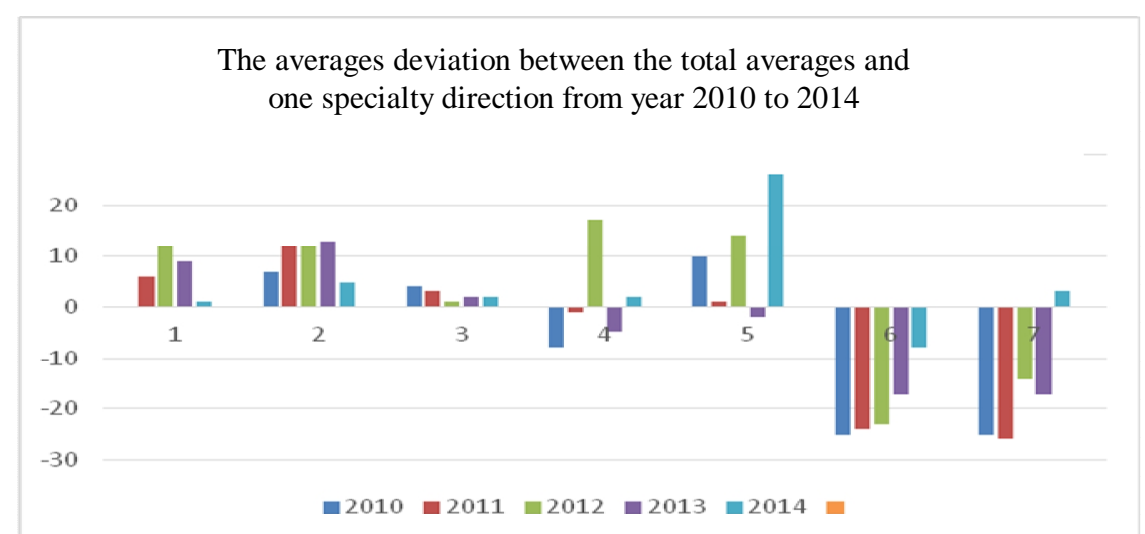

Fig 7. The averages deviation between the total averages of all the second-round exam students and the total averages of one specialty direction in the school of mechanical engineering of NJUST from year 2010 to 2014

\section{Countermeasures to improve the students source quality}

According to the postgraduate source analysis of NJUST in nearly five years, there were some main problems should be solved, including 1) limitation of narrow enrollment region, serious lack of the students who came 211 colleges; 2) the students who came from ourselves school have good comprehensive quality, but there were disadvantage of inbreeding; 3 ) the examinee regional excessive concentration, propaganda insufficient in universities at Midwest China; 4) Relative to other major, the scores of the students of the armament specialty were low. Through surveying, the students who mainly payed attention to the majors and study directions, in addition, they also focus on the location of the school. Nanjing, as the capital city of Jiangsu province, located at the intersection of Anhui, Zhejiang and Shanghai. So, it has the advantage of connecting developed area, at same time, it also has the influence of radiation economic less developed areas, such as Anhui, Jiangxi, Hunan and Hubei. So, the school should play their own advantages, master the characteristics of students in colleges and universities in the Midwest, enhance the propaganda, and to attract the best students.

Attract outstanding students by the characteristics of armament and advantage of discipline. Nanjing University of Science and Technology has shouldered the glorious mission since it has established, which is taking the lead and laying the foundation for the modernization of national defense. The university adheres to the belief that national interest is first, and establishes with the standard of domestic top level university. It has brought together a group of domestic top level scholars, and has built a set of complete academic system on armament in our country. It has good foundation and high starting point. In the next development, the university always sticks to the mission, regards strengthening defense as her duty, and takes armament specialty as the main line. Meanwhile, the school expands and improves the discipline constantly, so it has formed the feature of "three-dimensional ordnance", and the armament science and technology discipline continues to be first in the whole nation.Armament characteristic specialty includes sound, light, electricity, and magnetism, advanced manufacturing, intelligent material, intelligent, informatization, miniaturization, micromation and other multi-disciplinaries field. And it has achieved fruitful achievements in these areas, including the National Invention Awards and the National Progress Awards in S\&T, the national progress prize in defense science and technology, etc. The university has successively developed the first blast robot in our country, the first microscopic CT, the first autonomous ground unmanned platform, the first universal ultra-high pressure water jet cutting machine, the first intelligent checkout automobile for highway pavement, the first automatic identification system for signature authenticity and other high-tech achievements. So the school should rely on the preponderant discipline, and enhance the propaganda in the western key universities to attract high-quality military personnel.

Just like celebrity effect, the effect of the celebrated teachers has a strong appeal. The school should utilize the effect of the celebrated teachers to promote graduate enrollment propaganda. A graduate quality report of NJUST in 2014 shows: The school owns 7 academicians (including 5 
double hire academicians), 3 foreign academicians, 8 "Thousands of People Plan" experts, 2 "Ten Thousand People Plan" experts (including an elitist), 11 Yangtze River scholar Professors, 7 "National Outstanding Youth Fund" winners, 3 "National Teaching Masters Award" winners, 6 "973" chief scientists, 6 "National Expert with Remarkable Contributions" winners, 12 "New Century Talents Project" national candidates, 29 "New Century Excellent Talent Support Program" candidates of the Ministry of education, 22 "511 Talents Project" winners of the National Defense Science and technology industry, 193 Government special allowance winners, 5 Jiangsu Distinguished Professor, 6 "High-level Innovative and Entrepreneurial Talent Introduction Program" winners, 176 "333 high-level talent project" winners of Jiangsu Province, 114 " Qing-Lan Project” winners for colleges and universities of Jiangsu Province, 5 "Innovation team of development plan" teams of the Ministry of education, 5 national teaching teams, 8 national defense science and technology innovation teams, 11 innovation teams of Jiangsu Province. These celebrated teachers and excellent teams are very important resources, which should be mainly used in the enrollment propaganda or the network in order to attract outstanding students.

Giving full play to the advantages of excellent students, attracting good students by lineage and guide. Outstanding senior also play an important effect in the recruitment of students propaganda. According to the questionnaire survey of postgraduate students in school, $80 \%$ of the students approved the influence of the excellent elder, and they also had great influence on the choice of one's major.

\section{Conclusions}

According to the postgraduate source analysis of NJUST in nearly five years, there were some main problems to be solved, there are several flaws as follows: Fewer students came from key universities and serious in inbreeding, the examinee regional excessive concentration and the publicity area needs to be further expanded, and the nationwide examination score of the armament specialty students was low. According to the advantages of the school, some suggestions were given as follow: Attract outstanding students by the characteristics of armament and advantage of discipline, Exerting the effect of the celebrated teachers to attract outstanding students, Giving full play to the advantages of excellent students, attracting good students by lineage and guide. So the school should play their own advantages, master the characteristics of students in colleges and universities, enhance the propaganda, and to attract the best students.

\section{Acknowledgment}

This research is financially supported by 2014 annual postgraduate education and teaching reform research and practice project of Jiangsu province under grant number JGZZ14-019

\section{References}

[1] GaoDan, Lv Wei. A study on the recruitment quality of postgraduates in local universities__taking Shenyang Aerospace University as an example[J]. Journal of Shenyang Aerospace University. 2013, S, 74-76. In Chinese

[2] Chen Liwen, Chen shuna. Study on the enrollment quality of the academic postgraduates [J]. Further Education Research. 2011( 10) : 94-97. In Chinese

[3] Huo Dan. Research on Quality Assurance System of Graduate Education in China Under the Perspective of International Comparison[D]. Nanjing, Nanjing University of Aeronautics and Astronautics, 2013. In Chinese

[4] Luo Min. Graduate Enrollment Mechanism Based on Resource Allocation[D]. Wuhan, Huazhong University of Science and Technology, 2011. In Chinese 
[5] Tie Jiaxing. Research on training talent in defense science \& technology university for the need of defense science \&technology industry[D]. Harbin, Harbin Institute of Technology, 2009. In Chinese. 